\title{
A EFICÁCIA DA COMUNICAÇÃO INTERNA PARA PROMOÇÃO DA QUALIDADE ORGANIZACIONAL
}

\section{REVISÃO INTEGRATIVA}

FERREIRA, Marcia Regina Palma Rodrigues ${ }^{1}$

FERREIRA, Marcia Regina Palma Rodrigues. A eficácia da comunicação interna para promoção da qualidade organizacional. Revista Científica Multidisciplinar Núcleo do Conhecimento. Ano 06, Ed. 05, Vol. 08, pp. 22-39. Maio de 2021. ISSN: 2448-0959, Link de acesso: https://www.nucleodoconhecimento.com.br/saude/promocao-da-qualidade, DOI: 10.32749/nucleodoconhecimento.com.br/saude/promocao-da-qualidade

\section{RESUMO}

A comunicação é uma condição essencial ao ser humano, através dela os sentimentos são propagados, grupos sociais são criados e nascem os vínculos pessoais, fortalecendo, desta forma, o ambiente organizacional, através da difusão da comunicação interna. O objetivo deste trabalho é destacar a importância da comunicação interna para a qualidade no âmbito organizacional. Os conceitos utilizados abordam o tema e tem como objeto de estudo, a eficácia da comunicação interna para a promoção da qualidade organizacional. A questão de pesquisa: como a comunicação interna é eficaz para promover a qualidade no ambiente organizacional? Metodologia: o tipo de estudo proposto é bibliográfico em forma de revisão integrativa, com filtro de recorte temporal o período de 2013 a 2018. A coleta de material foi realizada no período de janeiro de 2019, através de pesquisas,

\footnotetext{
${ }^{1}$ Enfermeira especialista em Gestão e administração hospitalar e Enfermagem em centro cirúrgico, RPA e central de material e esterilização.
}

RC: 85039

Disponível em: https://www.nucleodoconhecimento.com.br/saude/promocao-da-qualidade 
utilizando as bases de dados: SCIELO, Google Acadêmico e BTTD. O motivo da escolha de revisão integrativa se deu pelo uso de resultados obtidos em pesquisas de forma sistemática, abrangente e ordenada. Conclusão: evidencia-se o fato de que a comunicação interna tem um papel fundamental no desenvolvimento estratégico das organizações.

Palavras-chaves: comunicação interna, comunicação organizacional, comunicação.

\section{INTRODUÇÃO}

A ação de transmitir uma mensagem e eventualmente receber outra mensagem como resposta, pode ser uma das variadas formas de definir a comunicação. Segundo Ferreira (2016), a comunicação face a face, na maioria das vezes informal, se apresenta como um rico canal, já que além da informação, representa outros elementos como: expressão, postura, gestos, entonação da voz, entre outros.

De acordo com Pereira (2017), a comunicação é uma condição inerente ao ser humano constituindo-se como inevitável na sua vivência com os outros, tanto no domínio das suas relações pessoais como laborais. Segundo Morais e Emboava (2015, apud Robbins, 2005) as pessoas passam 70\% (de suas horas de vigília) comunicando-se, escrevendo, lendo, falando, escutando. Ou seja, a comunicação é essencial para uma organização. E a organização, segundo Lemos e Barbosa (2016), é vista como um sistema complexo, formado por pessoas, processos, fluxos, redes, barreiras, meios, instrumentos e níveis de comunicação.

A comunicação é um fenômeno contínuo que acontece no ser humano em permanência Pereira (2017), tornando-se em troca de informações, um elemento de poder, configurando reações e atitudes que aceite conduzir ao alcance da influência.

Tomando como referência as informações mencionadas anteriormente, elaboramos o presente estudo que tem como linha de pesquisa desempenho organizacional e

RC: 85039

Disponível em: https://www.nucleodoconhecimento.com.br/saude/promocao-da-qualidade 
como área de predominância a importância da comunicação no ambiente organizacional, abordando como tema a eficácia da comunicação interna para promoção da qualidade organizacional.

Promovendo a interação das pessoas dentro da empresa, a comunicação interna surge como fortalecedora de vínculos entre colaboradores, envolvimento, satisfação e o início da promoção de um clima favorável ao comprometimento organizacional.

Desta forma, este estudo ressalta como problema: Como a comunicação interna é eficaz para promover a qualidade no ambiente organizacional?

Apresenta como objeto de estudo a eficácia da comunicação interna para a promoção da qualidade organizacional.

Traz como objetivo de estudo: destacar a importância da comunicação interna para a qualidade no âmbito organizacional.

Este estudo justifica-se pela necessidade de se enfatizar o valor da comunicação interna como um fator predominante ao desenvolvimento profissional, a criação de uma identidade e por conseguinte, procedendo em retorno satisfatórios para a organização, como alcance de metas, aumento de produtividade, entre outros.

Para a academia, este trabalho busca deixar o aprimoramento das pessoas envolvidas no processo de aprendizagem, sobre a comunicação e sua importância num ambiente organizacional e oferecer meios de estudo para novas pesquisas, de forma a trazer um benefício ao meio acadêmico.

\section{METODOLOGIA}

O tipo de estudo proposto é bibliográfico na modalidade de revisão integrativa, com abordagem descritiva, onde priorizamos fontes de pesquisa que foram citadas por

RC: 85039

Disponível em: https://www.nucleodoconhecimento.com.br/saude/promocao-da-qualidade 
autores conceituados no âmbito da metodologia científica. Sendo utilizado filtro de recorte temporal no período de cinco anos, utilizando os seguintes descritores: comunicação interna, comunicação organizacional, comunicação.

O motivo da escolha de revisão integrativa é pelo fato de utilizar métodos de busca claros e sistemáticos, além de contribuir para o desenvolvimento de teorias e a inclusão de estudos experimentais ou não. Além de possibilitar ao interessado, reconhecer os profissionais que mais investigam um assunto, suas áreas de atuação e suas contribuições mais relevantes; permite separar o achado científico de opiniões e ideias (ROMAN E FRIEDLANDER, 1988).

A revisão integrativa é um tipo de pesquisa que possui seis etapas que serão descritos a seguir:

$1^{\text {a }}$ etapa - identificação do tema e escolha da hipótese

O tema escolhido foi a eficácia da comunicação interna para promoção da qualidade; a questão norteadora é baseada na importância da comunicação interna para um melhor desenvolvimento organizacional, provendo desta forma a promoção da qualidade. A maneira escolhida para organização deste presente trabalho foi a utilização da internet na busca de dados, como em um sistema informatizado.

$2^{a}$ etapa: estabelecimento de critérios para inclusão e eliminação de estudos

. O critério de inclusão para o estudo foram: artigos que se atém ao tema proposto, no período de 2013-2018, na língua portuguesa e que possuem texto completo para consulta.

3ª etapa: definição da classificação dos estudos.

RC: 85039

Disponível em: https://www.nucleodoconhecimento.com.br/saude/promocao-da-qualidade 
Mendes, Silveira e Galvão (2008) afirmam que o revisor tem como objetivo, nesta etapa, organizar e sumarizar as informações de maneira concisa, formando um banco de dados de fácil acesso e manejo.

No banco de dados SCIELO, 270 artigos foram encontrados, após os critérios de inclusão/exclusão, apenas 3 foram considerados. Assim, sucessivamente com Google Acadêmico, dos 3090 artigos, apenas 3 artigos foram selecionados. E pelo BTTD dos 57 artigos, apenas 2 foram, considerados, somando assim, um total de 8 artigos. Os critérios de exclusão foram: abordagem inadequada do assunto, ano de publicação, língua estrangeira diversa do português, artigos acima de 5 anos de publicação, tendo como referência os anos de 2013-2018.

4ª etapa: avaliação dos estudos incluídos.

5ª etapa: análise e interpretação dos resultados.

6ª̣etapa: apresentação da revisão 
Fluxograma 1 - Busca Por Artigos Científicos.

\section{Artigos encontrados: 3417}

Descritor utilizado: Comunicação interna, comunicação organizacional, comunicação

SCIELO (270)

BDTD (57)

GOOGLE ACADÊMICO (3090)
(1)
(1)
(1)

Artigos que compreendem os últimos 5 anos (2013-2018)

(1)

98

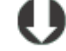

26

Artigos na língua portuguesa

(1)

73

\section{(1)}

23

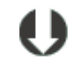

1420

Artigos que possuem texto completo

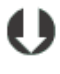

69

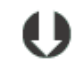

21

1315

Títulos que atém as questões do estudo

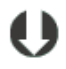

3

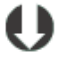

2

Em sumo $\mathbf{8}$ artigos foram considerados para o desenvolvimento do estudo

Fonte: elaborado pela própria autora, 2019.

RC: 85039

Disponível em: https://www.nucleodoconhecimento.com.br/saude/promocao-da-qualidade 
QUADRO 1 - ARTIGOS SELECIONADOS.

\begin{tabular}{|c|c|c|c|c|}
\hline $\mathrm{N}$ & Ano & Título & Autor & Base de Dados \\
\hline 1 & $\begin{array}{l}201 \\
7\end{array}$ & $\begin{array}{l}\text { Comunicação } \\
\text { organizacional } \\
\text { e gestão do } \\
\text { conhecimento } \\
\text { : um estudo } \\
\text { de revisão } \\
\text { sistemática }\end{array}$ & $\begin{array}{l}\text { LEMOS, } \\
\text { Ariane } \\
\text { Barbosa; } \\
\text { BARBOS } \\
\text { A, } \\
\text { Ricardo } \\
\text { Rodrigue }\end{array}$ & $\begin{array}{l}\text { 17., 2016, Salvador. Anais... } \\
\text { Salvador: UFBA, } 2016 .\end{array}$ \\
\hline 2 & $\begin{array}{l}201 \\
3\end{array}$ & $\begin{array}{l}\text { O } \\
\text { engajamento } \\
\text { e o processo } \\
\text { de } \\
\text { relacionament } \\
\text { o interno } \\
\text { mediado pela } \\
\text { comunicação } \\
\text { nas } \\
\text { organizações }\end{array}$ & $\begin{array}{l}\text { BEM, } \\
\text { Júlio } \\
\text { César de }\end{array}$ & RI_PUC_RS:oai:meriva.pucrs. br:10923/5489 \\
\hline 3 & $\begin{array}{l}201 \\
7\end{array}$ & $\begin{array}{l}\text { Comunicação } \\
\text { interna e } \\
\text { comprometim } \\
\text { ento } \\
\text { organizacional } \\
: \text { o caso da } \\
\text { Autoridade } \\
\text { para as }\end{array}$ & $\begin{array}{l}\text { NETO, } \\
\text { Cátia } \\
\text { Filipa; } \\
\text { CRUZ, } \\
\text { Sofia } \\
\text { Alexandra }\end{array}$ & $\begin{array}{l}\text { Sociologia, Dez 2017, Volume } 34 \text { Páginas } 47 \\
\text { - } 72\end{array}$ \\
\hline
\end{tabular}

RC: 85039

Disponível em: https://www.nucleodoconhecimento.com.br/saude/promocao-da-qualidade 


\begin{tabular}{|c|c|c|c|c|}
\hline & & $\begin{array}{l}\text { Condições do } \\
\text { Trabalho }\end{array}$ & & \\
\hline 4 & $\begin{array}{l}201 \\
7\end{array}$ & $\begin{array}{l}\text { A satisfação } \\
\text { dos } \\
\text { enfermeiros } \\
\text { com a } \\
\text { comunicação } \\
\text { organizacional } \\
\text { em contexto } \\
\text { hospitalar }\end{array}$ & $\begin{array}{l}\text { PEREIRA } \\
\text { Diana } \\
\text { Gomes }\end{array}$ & http://hdl.handle.net/10400.26/20967 \\
\hline 5 & $\begin{array}{l}201 \\
5\end{array}$ & $\begin{array}{l}\text { A importância } \\
\text { da } \\
\text { Comunicação } \\
\text { interna nas } \\
\text { organizações }\end{array}$ & $\begin{array}{l}\text { MORAIS, } \\
\text { Açucena } \\
\text { Vieira de ; } \\
\text { EMBOAV } \\
\text { A, Jéssica } \\
\text { Nascimen } \\
\text { to }\end{array}$ & $\begin{array}{l}\text { http://biblioteca.univap.br/dados/000026/0000 } \\
\text { 267e.pdf }\end{array}$ \\
\hline 6 & $\begin{array}{l}201 \\
7\end{array}$ & $\begin{array}{l}\text { Análise } \\
\text { situacional da } \\
\text { comunicação } \\
\text { interna com } \\
\text { ênfase nos } \\
\text { processos } \\
\text { logísticos de } \\
\text { uma } \\
\text { instituição } \\
\text { autárquica } \\
\text { hospitalar }\end{array}$ & $\begin{array}{l}\text { FERREIR } \\
\text { A, Rafael } \\
\text { Mayrink }\end{array}$ & $\begin{array}{l}\text { http://monografias.fjp.mg.gov.br/handle/1234 } \\
56789 / 2327\end{array}$ \\
\hline
\end{tabular}

RC: 85039

Disponível em: https://www.nucleodoconhecimento.com.br/saude/promocao-da-qualidade 


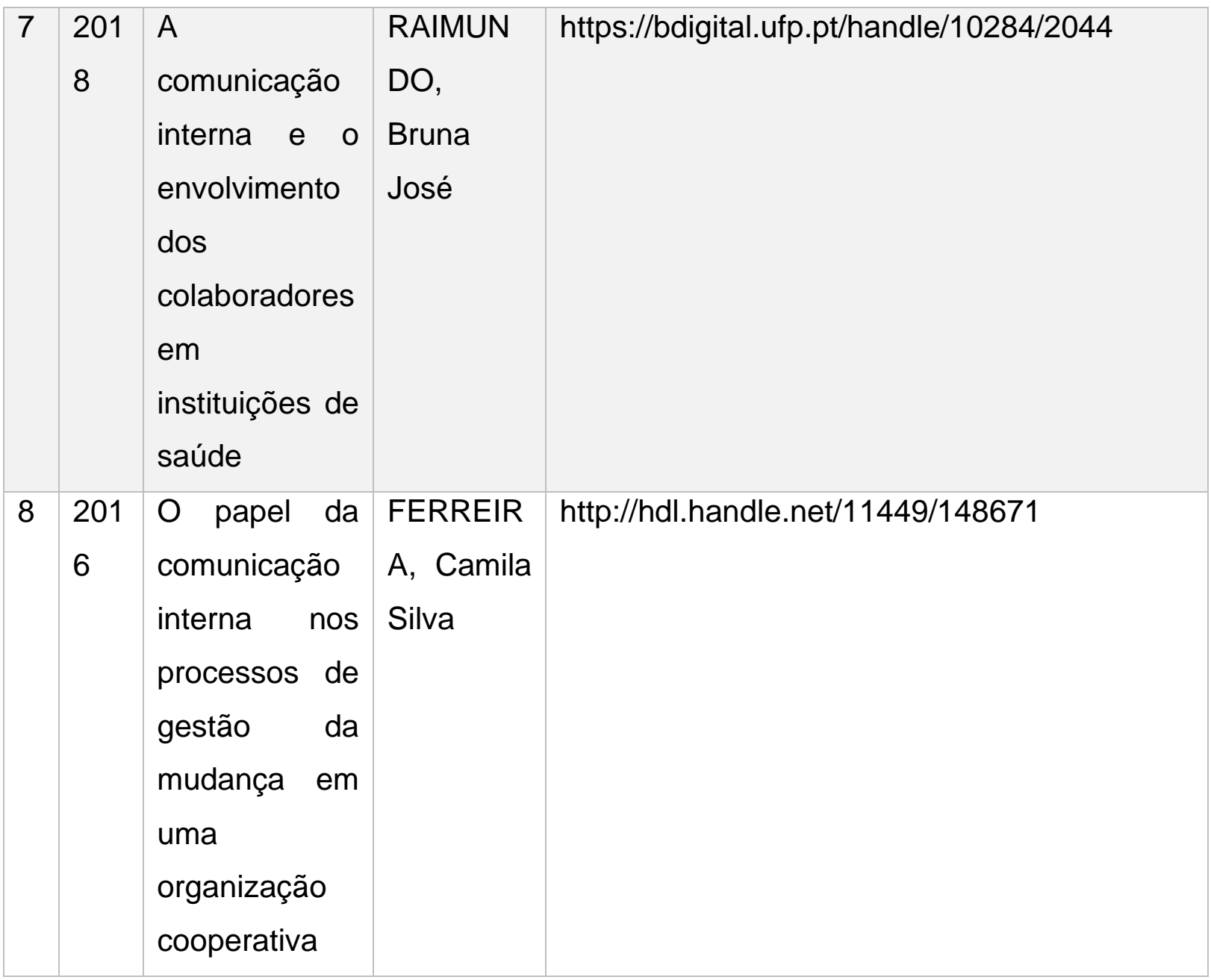

Fonte: elaborado pela própria autora, 2019.

Quadro 2 - Resultado Dos Artigos Selecionados.

\begin{tabular}{|c|c|c|c|}
\hline $\mathrm{N}^{\circ}$ & $\begin{array}{l}\text { OBJETIVO } \\
\text { ESTUDO }\end{array}$ & METODOLOGIA & RESULTADO \\
\hline & $\begin{array}{l}\text { Oferecer resposta ao } \\
\text { questionamento sobre } \\
\text { as dimensões teóricas }\end{array}$ & $\begin{array}{l}\text { Revisão sistemática da } \\
\text { literatura, a pesquisa } \\
\text { explora dimensões }\end{array}$ & $\begin{array}{l}\text { Os resultados do estudo } \\
\text { demonstram que a } \\
\text { Comunicação }\end{array}$ \\
\hline & Comunicação & teóricas $\quad \mathrm{da}$ & Organizacional atua na \\
\hline
\end{tabular}

RC: 85039

Disponível em: https://www.nucleodoconhecimento.com.br/saude/promocao-da-qualidade 


\begin{tabular}{|c|c|c|c|}
\hline & $\begin{array}{l}\text { Organizacional; e } \\
\text { identificar se há diálogo } \\
\text { ou alinhamento entre as } \\
\text { temáticas desta área } \\
\text { com a Gestão do } \\
\text { Conhecimento. }\end{array}$ & $\begin{array}{l}\text { Comunicação } \\
\text { Organizacional e analisa } \\
\text { o seu alinhamento com } \\
\text { a Gestão fontes } \\
\text { Conhecimento. Foram } \\
\text { avaliadas } \\
\text { secundárias, } \\
\text { recuperadas nas bases } \\
\text { de dados Emerald e } \\
\text { Science Direct } \\
\text { publicadas entre os anos } \\
\text { de } 2010 \text { e } 2015\end{array}$ & $\begin{array}{l}\text { divulgação de mensagens } \\
\text { para stakeholders, além } \\
\text { disso, suas ferramentas } \\
\text { são aplicadas para } \\
\text { estimular fluxos de } \\
\text { informação e a troca de } \\
\text { conhecimento. }\end{array}$ \\
\hline$?$ & $\begin{array}{l}\text { Identificar fatores de } \\
\text { engajamento das } \\
\text { pessoas, considerando- } \\
\text { se o relacionamento } \\
\text { interno mediado pela } \\
\text { comunicação nas } \\
\text { organizações. }\end{array}$ & $\begin{array}{l}\text { Pesquisa do tipo social, } \\
\text { com base empírica, } \\
\text { envolvendo } \\
\text { procedimentos } \\
\text { metodológicos } \\
\text { pesquisa-ação em uma } \\
\text { organização privada de } \\
\text { grande porte, líder no } \\
\text { seu segmento na região } \\
\text { sul do Brasil. }\end{array}$ & $\begin{array}{l}\text { Foi possível identificar } \\
\text { como fatores: processos } \\
\text { de comunicação interna } \\
\text { que valorizem o } \\
\text { relacionamento humano, } \\
\text { lideranças, processos de } \\
\text { identificação } \\
\text { organizacional, avaliação } \\
\text { de desempenho } \\
\text { valorização das pessoas. } \\
\text { Destaca-se assim, a } \\
\text { necessidade de valorizar } \\
\text { a comunicação como } \\
\text { meio de potencializar o } \\
\text { engajamento das pessoas } \\
\text { em uma organização } \\
\text { como base nos seus }\end{array}$ \\
\hline
\end{tabular}

RC: 85039 


\begin{tabular}{|c|c|c|c|}
\hline & & & $\begin{array}{l}\text { relacionamentos } \\
\text { humanos, especialmente, } \\
\text { através do papel de suas } \\
\text { lideranças no ambiente de } \\
\text { trabalho. }\end{array}$ \\
\hline 3 & $\begin{array}{l}\text { Analisar como as } \\
\text { estratégias de } \\
\text { comunicação interna } \\
\text { influenciam } \\
\text { comprometimento } \\
\text { organizacional dos } \\
\text { inspetores do trabalho } \\
\text { da Autoridade para as } \\
\text { Condições de Trabalho. }\end{array}$ & $\begin{array}{l}\text { Os dados foram obtidos } \\
\text { a partir de um inquérito } \\
\text { por questionário } \\
\text { aplicado a estes } \\
\text { profissionais, através do } \\
\text { qual discutiu-se a } \\
\text { relação entre as } \\
\text { variáveis } \\
\text { comunicação interna e } \\
\text { do comprometimento } \\
\text { organizacional. }\end{array}$ & $\begin{array}{l}\text { Concluiu-se que a } \\
\text { comunicação interna } \\
\text { influencia positivamente o } \\
\text { comprometimento } \\
\text { organizacional, sendo o } \\
\text { antecedente } \\
\text { significativo } \\
\text { comprometimento } \\
\text { normativo a comunicação } \\
\text { com o supervisor, e o do } \\
\text { comprometimento afetivo } \\
\text { o clima comunicacional. }\end{array}$ \\
\hline 3 & $\begin{array}{l}\text { Analisar como as } \\
\text { estratégias interna } \\
\text { comunicação } \\
\text { influenciam } \\
\text { comprometimento } \\
\text { organizacional dos } \\
\text { inspetores do trabalho } \\
\text { da Autoridade para as } \\
\text { Condições de Trabalho. }\end{array}$ & $\begin{array}{l}\text { Os dados foram obtidos } \\
\text { a partir de um inquérito } \\
\text { por questionário } \\
\text { aplicado a estes } \\
\text { profissionais, através do } \\
\text { qual discutiu-se a } \\
\text { relação entre as } \\
\text { variáveis } \\
\text { comunicação interna e } \\
\text { do comprometimento } \\
\text { organizacional. }\end{array}$ & $\begin{array}{l}\text { Concluiu-se que a } \\
\text { comunicação interna } \\
\text { influencia positivamente o } \\
\text { comprometimento } \\
\text { organizacional, sendo o } \\
\text { antecedente } \\
\text { significativo } \\
\text { comprometimento } \\
\text { normativo a comunicação } \\
\text { com o supervisor, e o do } \\
\text { comprometimento afetivo } \\
\text { o clima comunicacional. }\end{array}$ \\
\hline
\end{tabular}

RC: 85039

Disponível em: https://www.nucleodoconhecimento.com.br/saude/promocao-da-qualidade 


\begin{tabular}{|c|c|c|c|}
\hline & $\begin{array}{l}\text { Este estudo tem como } \\
\text { principal objetivo } \\
\text { analisar a satisfação } \\
\text { dos enfermeiros com a } \\
\text { comunicação } \\
\text { organizacional em dois } \\
\text { hospitais com diferentes } \\
\text { modelos de gestão com } \\
\text { recurso ao Questionário } \\
\text { de Satisfação com a } \\
\text { Comunicação de Downs } \\
\text { e Hazen (1977) }\end{array}$ & 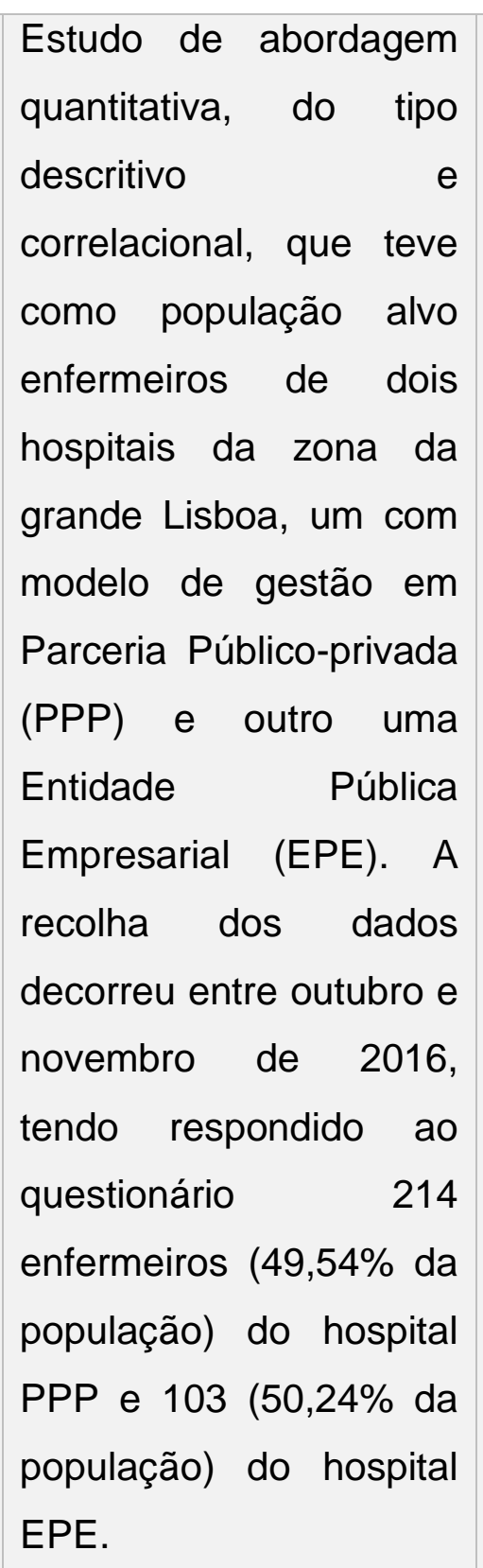 & $\begin{array}{l}\text { Foi possível comprovar } \\
\text { estatisticamente que } \\
\text { existem diferenças no } \\
\text { grau de satisfação entre } \\
\text { os enfermeiros dos dois } \\
\text { hospitais em sete itens do } \\
\text { questionário. Verificou-se, } \\
\text { no entanto, uma } \\
\text { percentagem significativa } \\
\text { de respostas "indiferente". } \\
\text { Dada a importância do } \\
\text { tema em estudo para a } \\
\text { profissão de enfermagem } \\
\text { e a necessidade de } \\
\text { realizar novos trabalhos } \\
\text { nesta área, a conclusão } \\
\text { do presente estudo } \\
\text { contempla as limitações } \\
\text { encontradas e indica } \\
\text { algumas sugestões de } \\
\text { melhoria para trabalhos } \\
\text { futuros. }\end{array}$ \\
\hline & $\begin{array}{l}\text { Mostrar a importância } \\
\text { da comunicação interna } \\
\text { nas organizações, por } \\
\text { meio de uma grande } \\
\text { reportagem impressa } \\
\text { para revista, voltada a }\end{array}$ & $\begin{array}{l}\text { Desenvolvido com base } \\
\text { em três eixos: a } \\
\text { pesquisa bibliográfica, } \\
\text { pesquisa de campo e } \\
\text { por meio de observação } \\
\text { das tendências e }\end{array}$ & $\begin{array}{l}\text { A comunicação interna } \\
\text { exige do jornalista muita } \\
\text { paciência, cuidado e } \\
\text { empenho. Transmitindo } \\
\text { da melhor maneira as } \\
\text { informações para os }\end{array}$ \\
\hline
\end{tabular}

RC: 85039

Disponível em: https://www.nucleodoconhecimento.com.br/saude/promocao-da-qualidade 


\begin{tabular}{|c|c|c|c|}
\hline & $\begin{array}{l}\text { pessoas que trabalham } \\
\text { com comunicação } \\
\text { corporativa, pretendem } \\
\text { trabalhar, empresários, } \\
\text { ou apenas curiosos, que } \\
\text { tenham interesse no } \\
\text { assunto. }\end{array}$ & $\begin{array}{l}\text { necessidades das } \\
\text { organizações no quesito } \\
\text { "comunicação } \\
\text { empresarial". }\end{array}$ & $\begin{array}{l}\text { colaboradores, colocando- } \\
\text { os a par de todas as } \\
\text { situações relacionadas ao } \\
\text { seu local de trabalho. } \\
\text { Enxergando os } \\
\text { funcionários como um dos } \\
\text { principais meios de } \\
\text { comunicação dentro e fora } \\
\text { das organizações, com } \\
\text { táticas para envolver e } \\
\text { motivá-los, gerando } \\
\text { resultados positivos para } \\
\text { o empreendimento. }\end{array}$ \\
\hline 6 & $\begin{array}{l}\text { Busca identificar pontos } \\
\text { de conexão entre } \\
\text { logística e comunicação } \\
\text { interna, e visualizar } \\
\text { como esta interação } \\
\text { ocorre na prática, na } \\
\text { realidade de uma } \\
\text { autarquia que presta } \\
\text { serviços de seguridade } \\
\text { social. }\end{array}$ & $\begin{array}{l}\text { Consiste } \\
\text { levantamento } \\
\text { bibliográfico a fim de } \\
\text { identificar e apresentar } \\
\text { conceitos teóricos de } \\
\text { logística e comunicação } \\
\text { separadamente e } \\
\text { realizadas entrevistas } \\
\text { com agentes chave } \\
\text { envolvidos na cadeia de } \\
\text { suprimentos de } \\
\text { medicamentos } \\
\text { materiais médicos. }\end{array}$ & $\begin{array}{l}\text { A interação vai muito além } \\
\text { das informações } \\
\text { encontradas em } \\
\text { referências. Por meio do } \\
\text { diagnóstico situacional, foi } \\
\text { possível identificar atores } \\
\text { principais e fluxos de } \\
\text { comunicação que } \\
\text { poderiam interferir na } \\
\text { logística hospitalar de } \\
\text { uma autarquia. }\end{array}$ \\
\hline 7 & $\begin{array}{ll}\text { Busca } & \text { informações } \\
\text { sobre o processo de }\end{array}$ & $\begin{array}{lr}\text { revisão de } & \text { literatura } \\
\text { abordando os } & \text { temas } \\
\text { associados } & \\
\text { à }\end{array}$ & $\begin{array}{l}\text { Observou-se que } 0 \\
\text { público pesquisado estava } \\
\text { insatisfeito com } 0\end{array}$ \\
\hline
\end{tabular}

RC: 85039 


\begin{tabular}{|c|c|c|c|}
\hline & $\begin{array}{l}\text { comunicação, as } \\
\text { principais ferramentas } \\
\text { utilizadas na instituição } \\
\text { e ainda sobre o } \\
\text { envolvimento } \\
\text { ambiente de trabalho, } \\
\text { utilizando a escala de } \\
\text { envolvimento } \\
\text { trabalho de } \\
\text { referência. }\end{array}$ & $\begin{array}{l}\text { comunicação } \\
\text { organizacional, } \\
\text { comunicação interna, o } \\
\text { envolvimento no } \\
\text { colaboradores dos } \\
\text { ambiente de trabalho e } \\
\text { também as práticas de } \\
\text { comunicação interna em } \\
\text { instituições de saúde e } \\
\text { um estudo qualitativo } \\
\text { com os líderes e } \\
\text { gestores do hospital, } \\
\text { juntamente com } \\
\text { aplicados questionários } \\
\text { quantitativos destinados } \\
\text { aos colaboradores e } \\
\text { profissionais da área } \\
\text { médica com o objetivo } \\
\text { de buscar informações } \\
\text { sobre o processo de } \\
\text { comunicação }\end{array}$ & $\begin{array}{l}\text { processo de comunicação } \\
\text { interna da organização, e, } \\
\text { consequentemente, } \\
\text { nível de envolvimento } \\
\text { também estava abaixo do } \\
\text { esperado. }\end{array}$ \\
\hline 8 & $\begin{array}{l}\text { Analisar o cenário da } \\
\text { comunicação interna e } \\
\text { gestão da mudança de } \\
\text { uma organização } \\
\text { cooperativa, } \\
\text { identificando a relação } \\
\text { entre essas duas áreas } \\
\text { e como elas podem }\end{array}$ & $\begin{array}{l}\text { Como metodologias são } \\
\text { utilizadas: 1) pesquisa } \\
\text { bibliográfica sobre } \\
\text { Comunicação, } \\
\text { Comunicação Interna, } \\
\text { Gestão da Informação, } \\
\text { Gestão do } \\
\text { Conhecimento, Gestão }\end{array}$ & $\begin{array}{l}\text { Identifica-se que a } \\
\text { Comunicação Interna atua } \\
\text { definindo estratégias para } \\
\text { transmitir as informações } \\
\text { aos colaboradores. Sendo } \\
\text { assim, é meramente } \\
\text { informativa e quase não } \\
\text { existe participação dos }\end{array}$ \\
\hline
\end{tabular}

RC: 85039

Disponível em: https://www.nucleodoconhecimento.com.br/saude/promocao-da-qualidade 
estar associadas.

da Mudança, Inovação e Cultura Organizacional; construção formal.

2) pesquisa de campo na Cooperativa Regional dos Cafeicultores em Guaxupé - Cooxupé -, subdividida em pesquisa documental, entrevistas semiestruturadas em profundidade observação participante.

Fonte: elaborado pela própria autora, 2019.

\section{REVISÃO DE LITERATURA}

\subsection{A COMUNICAÇÃO INTERNA COMO FORMA DE IDENTIDADE ORGANIZACIONAL}

A informação é resultado das relações sociais, mediadas pela comunicação (BEM, 2013). A perspectiva comunicacional dentro das organizações assume um lugar de destaque como suporte de toda a organização (PEREIRA, 2017). É um fator intrínseco de qualquer estrutura organizacional (FERREIRA, 2017).

A comunicação interna não trata apenas de transmissão de informação, podendo ser também utilizada para o envolvimento, interação e criação de valor (NETO E CRUZ, 2017). Desta forma então, instituindo, ampliando e amparando uma consciência grupal, promovendo visões compartilhadas e aumento o relacionamento no ambiente de trabalho. Porém, para que isto ocorra é necessário que a comunicação seja compreendida pelos envolvidos neste processo.

RC: 85039

Disponível em: https://www.nucleodoconhecimento.com.br/saude/promocao-da-qualidade 
Por Bem (2013), os relacionamentos ajudam a organização a gerenciar sua relação de dependência com os ambientes internos e externos. Sendo assim, aumentando ou diminuindo a autonomia da organização nestes ambientes.

A comunicação interna passou a conquistar papel estratégico e transformador dentro das organizações a partir de meados do século $X X$, como consequências das transformações que aconteciam em todo o mundo (FERREIRA, 2016).

A eficácia da comunicação interna está diretamente atrelada ao planejamento adequado, à cultura organizacional, à gestão participativa e às informações claras e coerentes (FERREIRA, 2016). Segundo ela gera consentimentos e produz a aceitação a qual institui os objetivos principais dela (RAIMUNDO, 2018). Ocupa um lugar de destaque no quadro dos benefícios da comunicação organizacional para o desenvolvimento estratégico das organizações (FERREIRA, 2016).

Segundo Raimundo (2018), inúmeros podem ser os efeitos da gestão da comunicação interna, são eles: sobrevivência da organização e, portanto, o fortalecimento de suas redes de relações; valorização interna de seus relacionamentos; ambiente de trabalho humanizado, colaborativo e ainda participativo.

\subsection{AGENTES DETERMINANTES PARA UMA COMUNICAÇÃO EFICAZ}

A comunicação é anterior ao estabelecimento de uma organização, sendo por isso inevitável falar em organizações sem se referir a comunicação como um elemento essencial para o seu sucesso (PEREIRA, 2017; apud WAGNER; BEZUIDENHOUT e ROOS, 2015).

A eficiência do trabalho da comunicação interna deve ser algo indiscutível dentro da empresa (MORAIS; EMBOAVA, 2015). Essa eficácia está baseada, segundo Bem RC: 85039

Disponível em: https://www.nucleodoconhecimento.com.br/saude/promocao-da-qualidade 
(2013), em: preservar a solidez dos relacionamentos; em promover espaços e momentos para os empregados escreverem ou contarem suas histórias correlacionando com a história da organização; no processo contínuo de integração vivencial, reflexivo e participativo; e na oportunidade de os empregados serem ouvidos.

De acordo com Morais e Emboava (2015, apud ROBBINS, 2005) são quatro as funções básicas da comunicação: controle, motivação, expressão emocional e informação:

- Controle: age diretamente no comportamento das pessoas de diversas maneiras. As organizações possuem hierarquias e orientações formais que devem ser seguidas pelos funcionários;

- Motivação: estabelecer metas específicas, dar feedback do progresso em relação a elas e o reforço do comportamento desejável estimulam e requerem comunicação.

- Expressão emocional: a comunicação que ocorre dentro do grupo é um mecanismo fundamental para que seus membros expressem suas frustações ou sentimentos da satisfação e também suas necessidades sociais;

- Informação: esta é a função final desempenhada pela comunicação e se relaciona como um papel de facilitadora de decisões.

Nenhuma das quatros funções é mais importante do que a outra, todas são fundamentais e devem manter-se interligadas para que as organizações tenham bom desempenho.

RC: 85039

Disponível em: https://www.nucleodoconhecimento.com.br/saude/promocao-da-qualidade 


\subsection{OS TIPOS DE COMUNICAÇÃO}

Há diversos métodos e formas de comunicação que podem ser utilizados no ambiente organizacional para a troca de mensagens. São eles: comunicação oral, comunicação escrita, a comunicação não-verbal e a comunicação eletrônica.

Dentre a comunicação oral podemos citar a sua utilização em palestras, debates e outros meios informais como conversas. Já na escrita utiliza memorandos, cartas e e-mails, registros, relatórios, manuais, entre outros. A não-verbal, movimentos corporais e gestos e a eletrônica, a que utiliza a tecnologia da informação por meio de e-mails, videoconferências, entre outros.

Segundo Ferreira (2017), depende-se de um fluxo para a comunicação ser realizada necessita-se de um fluxo, onde temos a existência de um propósito ou a mensagem a ser transmitida, que irá passar de uma fonte ou emissor para um receptor. Logo Pereira (2017), define os quatro fluxos de comunicação: o descendente, o ascendente, o lateral/horizontal e o diagonal.

A comunicação descendente serve principalmente para transmitir informações, fluindo dos níveis hierárquicos superiores para os inferiores e o ascendente no sentido oposto. A comunicação horizontal, entre pessoas do mesmo nível hierárquico, permite a coordenação do trabalho, a partilha de informações e a resolução de problemas interdepartamentais. E o diagonal, ocorre onde a comunicação é eficaz através de nenhum dos fluxos anteriores, sendo necessário utilizar canais alternativos e ultrapassar alguma cadeia hierárquica (PEREIRA, 2017; apud CUNHA et al, 2004).

Uma outra forma de comunicação aceita e positiva é o feedback, pois através dele é possível sanar dúvidas e Ferreira (2016; apud ARGENTIL, 2006, p. 188) afirma que

RC: 85039

Disponível em: https://www.nucleodoconhecimento.com.br/saude/promocao-da-qualidade 
"nenhum outro método funciona tão bem, e nenhum "ajuste rápido" satisfará a necessidade básica de interação com os demais funcionários.

De fato, para as organizações, independentemente de seu tamanho e ramo de atuação, torna-se essencial a integração de seus processos comunicativos, em função do fortalecimento do conceito institucional, mercadológico e corporativo junto à sociedade e corporativo junto à sociedade (LEMOS E BARBOSA, 2016; apud KUNSCH, 2008).

Há ainda quatros princípios de comunicação para uma gestão eficaz, segundo Bem (2013, apud GRUNING, 2009, p. 87 e 88), que são utilizadas em momentos de crises: princípio do relacionamento, onde facilita momentos de mudanças organizacionais; princípio da responsabilidade, onde a organização é responsável por administrar as crises, mesmo que não seja a culpada; princípio da transparência, fornece informações pertinentes em todas as fases da crise, aos seus empregados; princípio da comunicação simétrica, a organização necessita preservar os interesses dos seus empregados tanto quanto os organizacionais no momento do início da crise.

\section{DISCUSSÃO}

A organização depende das relações das pessoas, mediadas pela comunicação, para atingir seus objetivos por meio de sua estrutura organizacional (BEM, 2013). O colaborador tem além de suas responsabilidades organizacionais, uma vida social e convívio com várias outras pessoas e quanto mais socializar, buscar informações, mais ampliará a sua visão acerca de diversos assuntos. E o colaborador, segundo Morais e Emboava (2015), é a propaganda viva dos trabalhos desenvolvidos pelas organizações, por isso talvez a comunicação interna tenha se tornado uma ação tão importante dentro das empresas.

RC: 85039

Disponível em: https://www.nucleodoconhecimento.com.br/saude/promocao-da-qualidade 
A comunicação é uma das formas mais eficazes de negociação e de colaboração (BEM, 2013). Na organização ela permite, segundo Pereira (2017), a realização de diferentes ações que vão desde a interação com colegas, superiores e clientes até a obtenção ou transmissão de informação junto dos mesmos. Entre colegas, a comunicação permite a integração de novos elementos nas equipes através de transmissão de conhecimentos acerca das normas de trabalho e de conduta na organização. E refletem no desempenho pessoal, afetando os resultados da organização (BEM, 2013).

Por Lemos e Barbosa (2016; apud GUITIÉRREZ-GARCIA et al., 2015), a relação entre compartilhamento e comunicação definem quatro dimensões e princípios do diálogo interpessoal, quais sejam: 1- escuta, abertura para o outro; 2 - a busca da verdade; 3 - a perspectiva orientada para a mudança; e 4 - a resposta. Com estas definições, pode haver equilíbrio entre a comunicação organizacional, pois há a capacidade de responder às demandas de partes interessadas.

A comunicação interna afeta positivamente a satisfação no trabalho e a componente afetiva do comprometimento organizacional, apenas se as empresas promoverem a comunicação entre os trabalhadores (NETO E CRUZ, 2017). O colaborador, quando sabe que seu trabalho tem significado e tem representação no todo da organização, da importância das tarefas que realiza, do que produz, o desempenhará com mais eficiência (MORAIS E EMBOAVA, 2015). E hoje em dia, os gestores estão cada vez mais conscientes de que trabalhadores insatisfeitos podem dar mais despesa e ser prejudicial para a eficácia da organização (PEREIRA, 2017; apud CARICATI et al., 2014).

De acordo com Pereira (2017; apud DOWNS E HAZEN, 1977) existem diversas ações que os gestores podem desenvolver capazes de promover a satisfação com a comunicação dos colaboradores, nomeadamente:

RC: 85039

Disponível em: https://www.nucleodoconhecimento.com.br/saude/promocao-da-qualidade 
- Explicar as políticas da organização para dar resposta às questões dos colaboradores;

- Notificar os colaboradores acerca das mudanças que ocorrem na organização através de fontes oficiais;

- Dar liberdade aos colaboradores para fazer sugestões ou reclamações aos seus superiores;

- Possibilitar aos colaboradores acessibilidade e proximidade aos seus superiores;

- Expressar apreço pelo desempenho dos colaboradores.

Quando os gestores não envolvem os colaboradores na maioria das tomadas de decisões, estes se sentem alienados e indispostos para o trabalho (RAIMUNDI, 2018; apud ARGENTI, 2011). Deste modo é imprescindível que a gerência reconheça que deve repassar as informações para os servidores e se souber ouvilos, estes se envolverão nas suas atividades laborais sendo capazes de levar a meta da organização à diante (RAIMUNDO, 2018).

A comunicação deve ser um processo de duas vias, os funcionários acreditam que quando suas ideias são solicitadas e quando se compromete para dar um retorno, a administração os escute e os atenda (RAIMUNDO, 2018).

\section{CONSIDERAÇÕES FINAIS}

O presente estudo se propôs a demonstrar como a comunicação interna é eficaz em um ambiente organizacional e reafirmar a importância da comunicação para promoção da qualidade.

RC: 85039

Disponível em: https://www.nucleodoconhecimento.com.br/saude/promocao-da-qualidade 
A metodologia baseada em estudo bibliográfico na modalidade revisão integrativa permitiu uma síntese dos resultados de pesquisas científicas em torno da temática deste trabalho.

Da análise dos textos selecionados, constatou-se que a comunicação interna influencia positivamente o comportamento organizacional e sua eficácia se reflete na produtividade da empresa, sendo necessária para a qualidade no ambiente de trabalho.

Nos textos analisados, evidencia-se o fato de que a comunicação interna tem um papel fundamental no desenvolvimento estratégico das organizações e para sua difusão e eficiência são necessários quatro elementos envolvidos: controle, motivação, expressão emocional e informação.

Observamos que, dentro do recorte proposto e das fontes de pesquisa utilizadas, o quantitativo de estudo realizado nos últimos 5 anos (2013-2018) acerca da temática abordada resultou em apenas 8 textos. Os elementos necessários ao desenvolvimento estavam presentes nestes textos, e todos convergiam para corroborar com a proposta do estudo.

\section{REFERÊNCIAS}

BEM, Júlio César de. 0 engajamento e o processo de relacionamento interno mediado pela comunicação nas organizações. 2013. 125f. Dissertação (Mestrado) - Pontifícia Universidade Católica do Rio Grande do Sul. Faculdade dos Meios de Comunicação Social. Programa de Pós-Graduação em Comunicação Social. Brasil

FERREIRA, Camila Silva, O papel da comunicação interna nos processos de gestão da mudança em uma organização cooperativa. 2016. 125f. - Dissertação

RC: 85039

Disponível em: https://www.nucleodoconhecimento.com.br/saude/promocao-da-qualidade 
(Mestrado) -Universidade Estadual Paulista. Faculdade de Arquitetura, Artes e Comunicação, Bauru

FERREIRA, Rafael Mayrink, Análise situacional da comunicação interna com ênfase nos processos logísticos de uma instituição autárquica hospitalar. 2017. 56f. Monografia - Fundação João Pinheiro - Especialização em Administração Pública, Planejamento e Gestão Governamental, Belo Horizonte

LEMOS, Ariane Barbosa; BARBOSA, Ricardo Rodrigues. Comunicação Organizacional e gestão do conhecimento: um estudo de revisão sistemática. 17f,2016, Salvador. Anais, Salvador: UFBA, 2016.

MORAIS, Açucena Vieira de; EMBOAVA, Jéssica Nascimento, A importância da comunicação interna nas organizações. 2015. 47f. Monografia - Universidade do Vale do Paraíba - Graduação em Faculdade de Ciências Sociais Aplicadas e Comunicação, São José dos Campos

NETO, Cátia Filipa; CRUZ, Sofia Alexandra. Comunicação interna e comprometimento organizacional: o caso da Autoridade para as Condições do

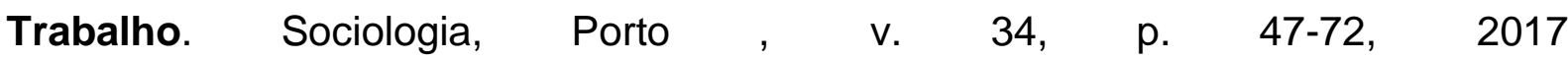
http://www.scielo.mec.pt/scielo.php?script=sci_arttext\&pid=S0872-

$34192017000300004 \&$ lng $=$ pt\&nrm=iso

PEREIRA, Diana Gomes, A satisfação dos enfermeiros com a comunicação organizacional em contexto hospitalar. 2017. 63f. - Dissertação (Mestrado) Escola Superior de Enfermagem de Lisboa, Curso de Especialização de Gestão em Enfermagem, Lisboa

RAIMUNDO, Bruna José, A comunicação interna e o envolvimento dos colaboradores em instituições de saúde. 2018. 99f. Universidade Fernando Pessoa Faculdade de Ciências Humanas e Sociais Departamento de Ciências

RC: 85039

Disponível em: https://www.nucleodoconhecimento.com.br/saude/promocao-da-qualidade 
Empresariais e da Comunicação FCHS (DCEC), Brasil, 2018. , http://hdl.handle.net/10284/7109.

Enviado: Agosto, 2020.

Aprovado: Maio,2021.

RC: 85039

Disponível em: https://www.nucleodoconhecimento.com.br/saude/promocao-da-qualidade 